\section{Two-Stage Treatment of Facial Asymmetry Caused by Unilateral Condylar Hyperplasia}

Samuel Porfírio Xavier ${ }^{1,2}$, Thiago de Santana Santos ${ }^{1}$, Erick Ricardo Silva ${ }^{1}$, Ana Célia Faria ${ }^{1}$, Francisco Verissimo de Mello Filho ${ }^{2}$

Condylar hyperplasia $(\mathrm{CH})$ is a rare, self-limiting process manifesting between the first and third decades of life. $\mathrm{CH}$ causes facial asymmetry and derangement of the occlusion. Management involves resection of the condylar head and orthognathic surgery. This paper describes the case of a 37-year-old woman with spontaneous onset of $\mathrm{CH}$ over a span of approximately 25 years. The condition was managed with resection of the condyle alone, which dramatically improved facial asymmetry and altered the occlusion within a few months of follow up. Orthodontic treatment was then carried out and the patient underwent orthognathic surgery after 3 years. The patient is currently satisfied with her appearance and function and there are no signs of recurrence.
'Department of Oral and Maxillofacial Surgery and Periodontology, Ribeirão Preto Dental School, USP - University of São Paulo, Ribeirão Preto, SP, Brazil ${ }^{2}$ Department of Ophthalmology, Otorhinolaryngology and Head and Neck Surgery, Integrated Center for the Study of Facial Deformities (C.1.E.D.E.F.), Ribeirão Preto Medical School, USP - University of São Paulo, Ribeirão Preto, SP, Brazil

Correspondence: Prof. Dr. Samuel Porfírio Xavier, Avenida do Café, s/n, 14040-904 Ribeirão Preto, SP, Brasil. Tel: +55-16-36023980. e-mail: spx@forp.usp.br

Key Words: condylar hyperplasia, condylar resection, asymmetry, orthognatic surgery.

\section{Introduction}

Mandibular condylar hyperplasia $(\mathrm{CH})$ is a rare condition that was first described by Robert Adams in 1836 as caused by the overdevelopment of the mandible, creating functional and esthetic problems (1). It has been also called hemimandibular hypertrophy (2), temporomandibular joint (TMJ) condylar hyperplasia (3) and hypercondylia (4). $\mathrm{CH}$ is a distinct, unilateral disorder characterized by diffuse enlargement of the condyle, the condylar neck and the ramus and body of the mandible, thus affecting facial symmetry and occlusion, and may be associated with pain and dysfunction (1). No comparable pathology has been described on any other joint. This disorder is self-limiting, but the asymmetry progresses as long as it remains active and is accompanied by changes in the occlusion (3).

Obewegeser and Makek (5) classified asymmetry associated with $\mathrm{CH}$ into three categories: hemimandibular hyperplasia, causing asymmetry on the vertical plane; hemimandibular elongation, resulting in asymmetry on the transverse plane; and a combination of the two types. The first type is caused by unilateral growth on the vertical plane and is characterized by a sloping rima oris, with almost no deviation of the chin, and intraorally by increased height of the maxillary alveolar bone and downward deviation of the oclusal plane on the ipsilateral side. If the maxillary plane fails to follow the mandibular plane, an open bite may develop on the same side. Most commonly, the mandibular midline is straight, but may shift ipsilaterally. Radiologically, Obewegeser and Makek (5) reported that the condyle appears enlarged; its head is usually irregular and deformed and its neck is thickened and elongated, with coarse trabeculae filling the condyle. The mandibular angle is typically round, with the canal in a low position. Joint pain is reported by $70 \%$ of patients (6). Hemimandibular elongation (the second type of $\mathrm{CH}$ ) is associated with chin deviation toward the contralateral side, with no vertical asymmetry. Intraorally, the mandibular midline deviates to the unaffected side, while the contralateral mandibular molars deviate lingually in attempt to remain in occlusion. However, crossbite may develop on the contralateral side. The occlusal plane is maintained with no deviation. The condyle has normal shape and size, but its neck may be slender, with an elongated ascending ramus. The third type of $\mathrm{CH}$ is a combination of the first two types (5).

This paper reports the case of an adult female patient in whom $\mathrm{CH}$ was managed by a two-stage treatment involving high condylectomy followed by orthognathic surgery.

\section{Case Report}

A 37-year-old female patient presented to the Oral and Maxillofacial Clinic of the School of Dentistry of Ribeirão Preto, University of São Paulo, Brazil, complaining of progressive facial deformity and changes in her facial appearance for approximately 25 years. At the age of 12 years, she started to notice that her lower jaw was deviating to the left. The condition was asymptomatic and there was no history of trauma or recurrent ear infection. Her medical history was unremarkable and there was no family history of skeletal disease or any other chronic disease. The extraoral examination revealed a concave facial profile with severe facial asymmetry; the chin was shifted to the left. Lip competence was observed, but the left commissure was shifted upward and the right was shifted downward (Fig. 1A). Upon mouth opening (35 
$\mathrm{mm})$, the lower jaw deviated to the left and the abnormal prominence of the right condyle could be seen and palpated during its restricted movement. The swelling was hard and
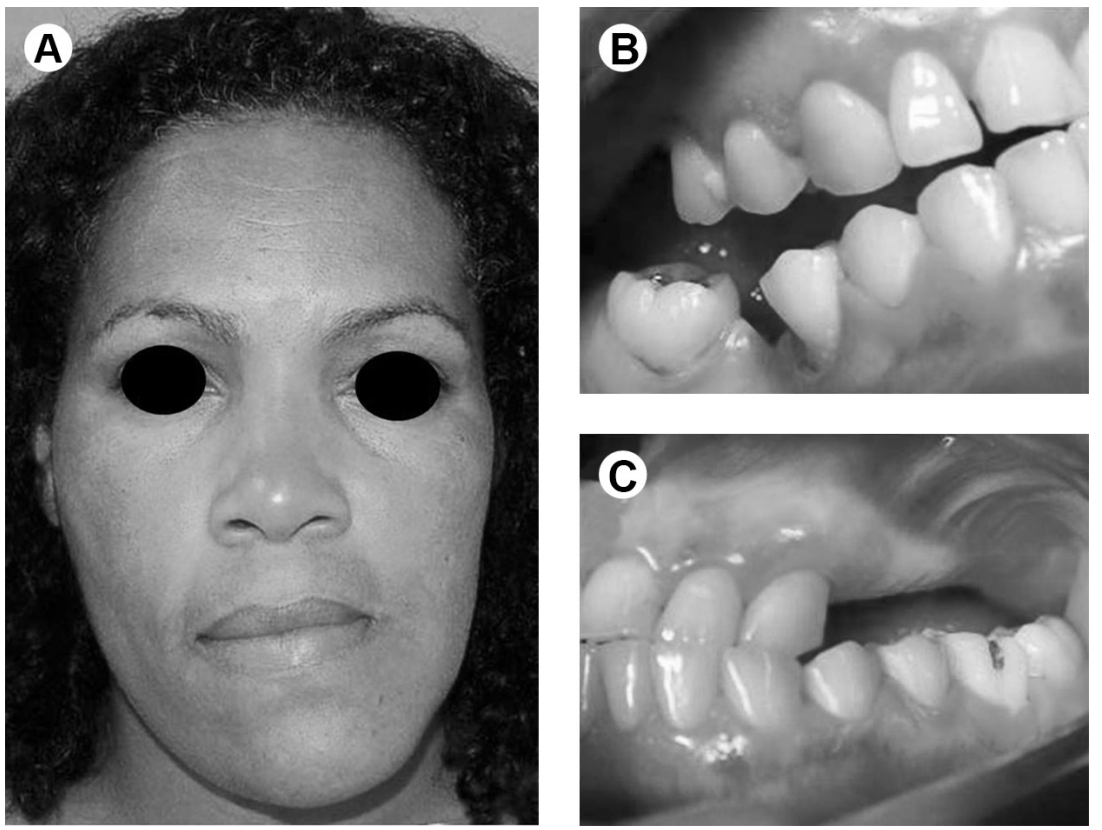

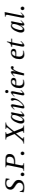

Figure 1. A: Severe derangement of occlusion - cant of occlusion. B: Left crossbite. C: right posterior open bite.
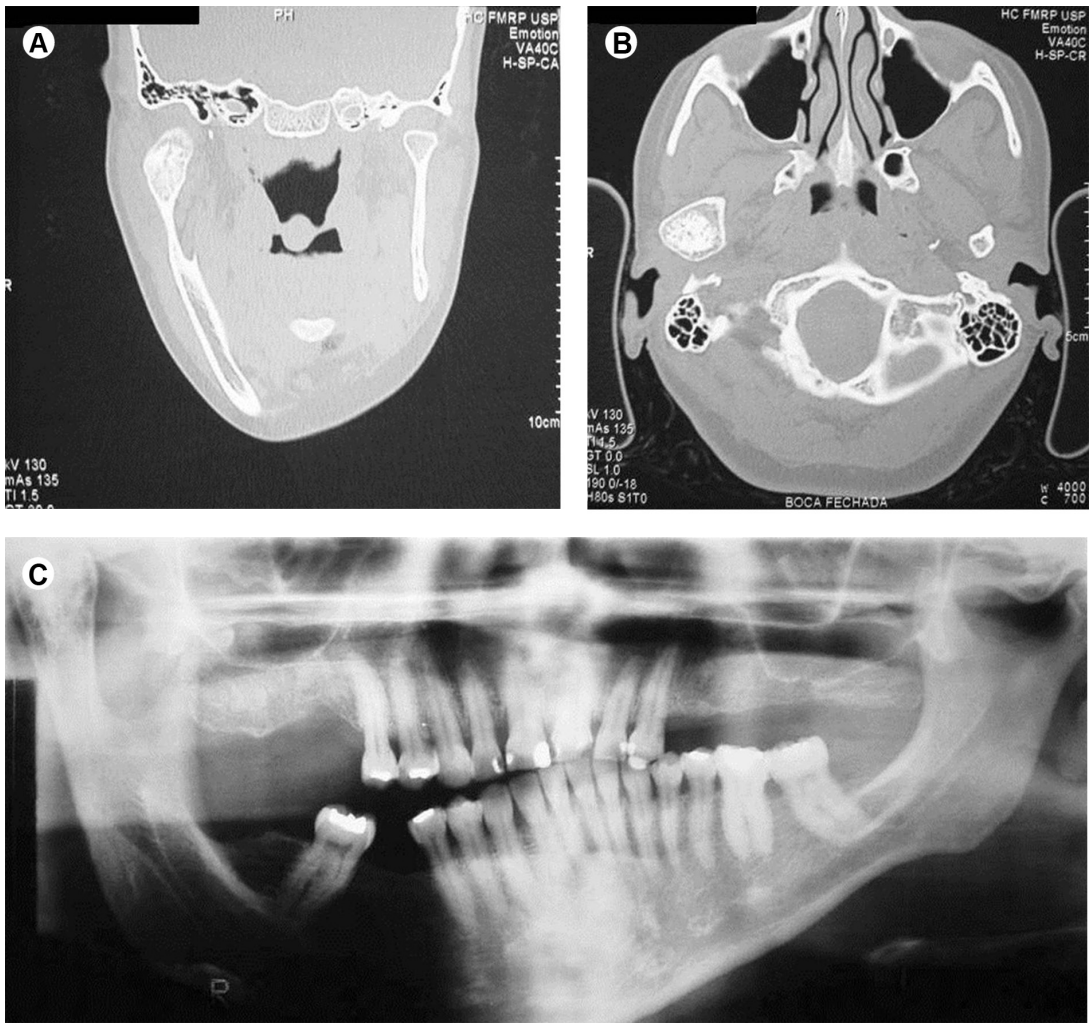

Figure 2. Images showing right condylar hyperplasia. A: Coronal CT. B: Axial CT. C: Panoramic radiograph. non-tender. Right condylar movement was restricted and the mass was visible when the patient opened her mouth. Intraorally, there was severe derangement and canting of the occlusion. The mandibular teeth were shifted to the left side, with a crossbite/reverse bite on the same side (Fig. 1B), and a posterior open bite was observed on the right side (Fig. 1C). The net result of the growth was translational rotation of the mandible to the left. Investigations included a panoramic radiograph, cephalogram, computed tomographic scan (axial and coronal) and threedimensionally reformatted images (Figs. 2A and 2B). The radiographic images showed enlarged condyle, ramus, angle and body on the right side of the mandible (Fig. 2C). The orthognathic work up included clinical photography, study models, jaw prototyping and cephalometric analysis. Analysis of the study models revealed anteroposterior prognathism at the incisor level and vertical overbite measuring 4 $\mathrm{mm}$. There was a scissor bite on the right side and a crossbite on the left side posteriorly, with a right shift of the mandibular dental midline. Magnetic resonance imaging (MRI) showed normality of the soft tissues in the TMJ region and scintigraphy was compatible with right unilateral condylar hyperplasia, based on the high uptake of radioactive tracer in this region (Fig. 3A). The orthognathic work up led to a problem list and the comprehensive management plan was staged. Stage 1 was to remove the growth center and restore temporomandibular joint function via mechanics of the functional matrix. Stage 2 was to reevaluate the patient and consider preorthognathic surgery, orthodontic treatment, and orthognathic surgery (maxillary reposition with bone graft in the posterior region, mandible with left side advancement and right side setback). Under nasotracheal intubation, a preauricular incision 
A
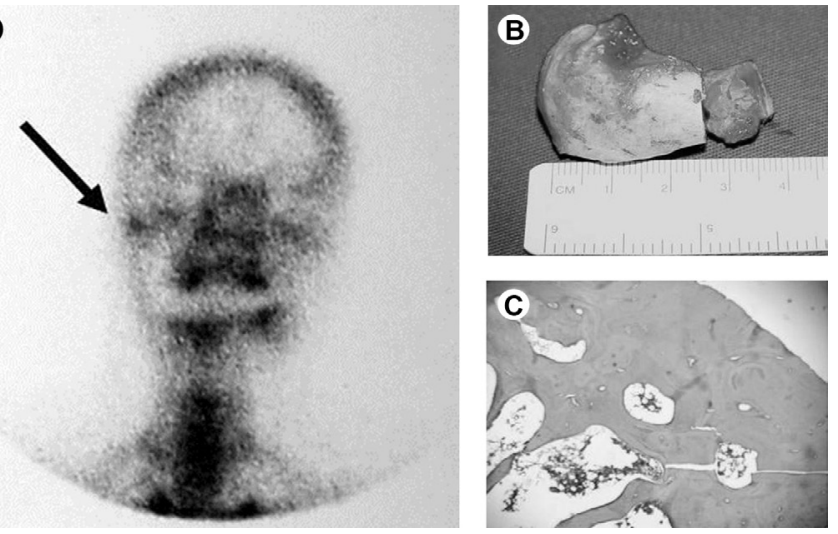

Figure 3. A: Scintigraphy showing high uptake of radioactive tracer in right condyle. B: Condylar head. C: Photomicrograph showing areas of hyaline cartilage and osseous tissue.

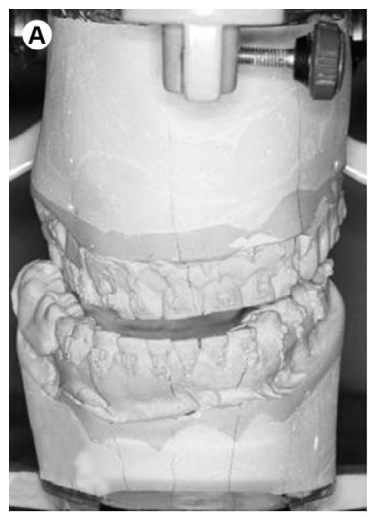

C
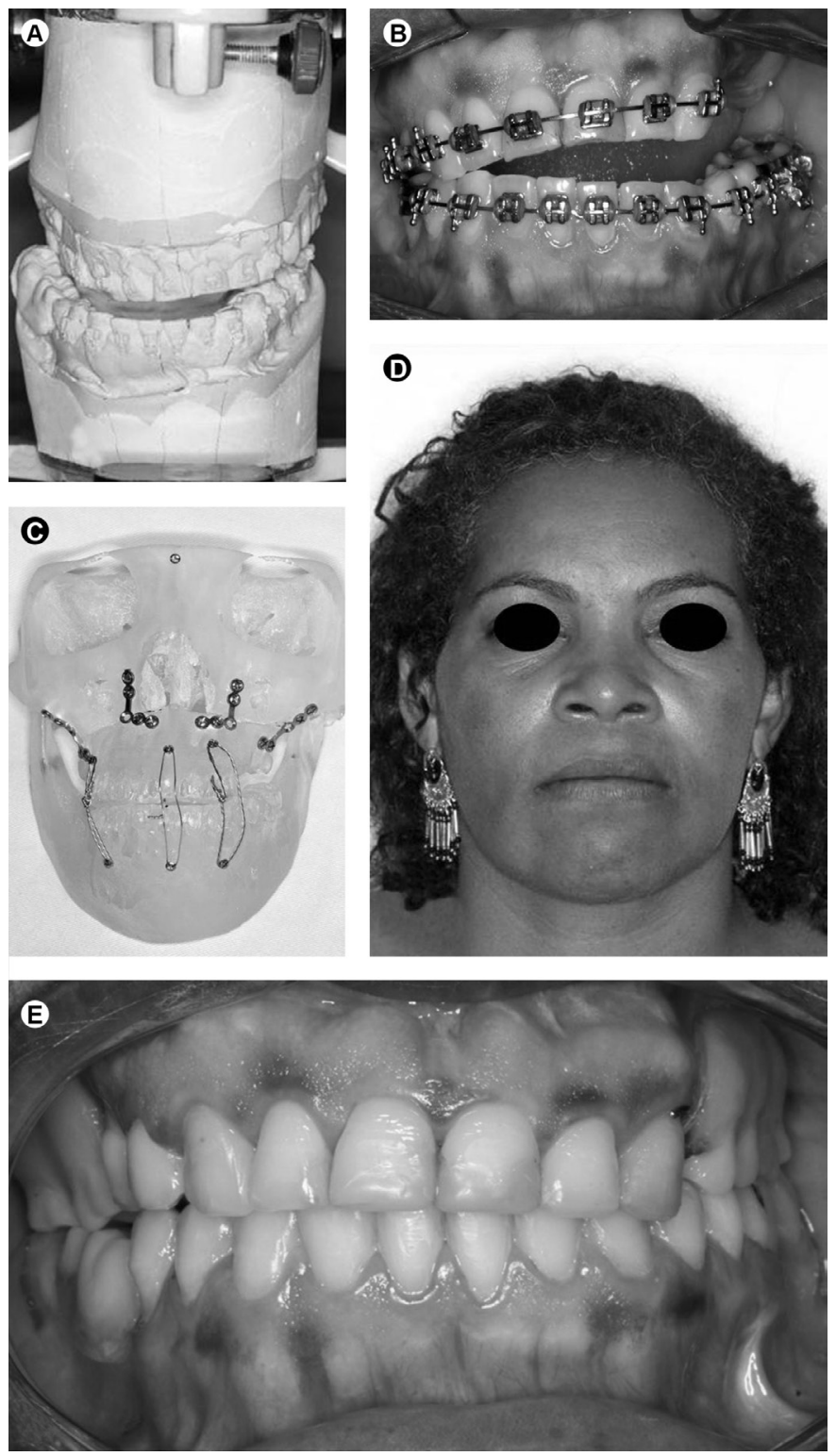

Figure 4. A: Pretreatment study models for orthognathic surgery. B: Altered occlusion after condylar removal. C: Jaw prototyping. D: Postoperative aspect 3 years after orthognathic surgery. E: final dental occlusion was made with a temporal extension. The temporal fascia was exposed and a T-incision was made over the zygomatic arch and the head and neck of the condyle. Precaution was taken to preserve the temporal branch of the facial nerve. A condylectomy was performed to remove the hyperplastic condylar head (Fig. 3B); the meniscus was spared and the bony edges of the residual neck were smoothened. The wound was closed in layers, with the placement of an in situ drain to minimize the drainage of the hematoma. The histopathologic examination confirmed that the enlargement was a hyperplastic process (Fig. 3C). Three years later, the patient underwent orthognathic surgery, as previously planned (Figs. 4A, 4B and $4 \mathrm{C})$. The patient was followed up and the mandible attained optimal symmetry with the correct occlusal relationship of the jaws in three years. The patient was satisfied and desired no further treatment (Fig. $4 \mathrm{D}$ and $4 \mathrm{E})$.

\section{Discussion}

The pathogenesis of $\mathrm{CH}$ occurring in the TMJ alone remains unclear. It is not known what triggers a condyle to suddenly start growing and become hyperplastic. The possible causes include trauma followed by excessive proliferation in the repair process, genetic causes, increase in functional loading of the TMJ, hormonal influences, arthrosis, infection and hypervascularity $(2,7)$. The differential diagnosis of condylar lesions generally includes condylar hyperplasia, giant-cell tumor, fibroosteoma, myxoma, fibrous dysplasia, fibrosarcoma, chondrosarcoma, osteoma, osteoblastoma, chondroma, chondroblastoma and osteochondroma $(8,9)$. However, the diagnosis of condylar hyperplasia can usually be made by a combination of clinical and radiological findings.

Simultaneous TMJ and orthognathic surgery for the treatment of patients with skeletal facial disorders and coexisting temporomandibular disorder (TMD) is controversial in the literature. Wolford (10) states that one benefit of concomitant surgery is providing patients with coexisting TMJ pathology and dentofacial deformities the possibility of avoiding the iatrogenic malocclusion that may occur when performing open TMJ surgery alone. In orthognathic surgery, the identification of a correct condyle-fossa relationship is essential to the precise positioning of the proximal and distal segments and ultimately affects the stability of the procedure. In the combined approach, the condyle-fossa relationship is all the more dependent on the experience of the surgeon. 
The one-stage approach can make an overall improvement in TMJ symptoms after orthognathic surgery, possibly obviating the need for TMJ surgery (10). However, such surgery has also been reported to create TMJ symptoms and/or aggravate existing ones $(11,12)$. Moreover, the one-stage approach leads to an increase in operating and general anesthesia times, with an attendant increase in associated complications, hospitalization and, ultimately, financial cost to the patient (13). Therefore, a two-stage approach is indicated for the treatment of patients with concomitant TMD and skeletal facial deformities, as in HC.

Basic considerations in the management of facial asymmetry caused by active $\mathrm{CH}$ must include the control of the growth process to allow a more balanced facial development. If there is evidence of abnormal condylar growth, condylar surgery should be undertaken before a severe facial deformity develops (14). The removal of the condyle is expected to arrest the excessive, disproportionate growth of the mandible in the diseased region and eliminate the need for additional surgical interventions in most cases. Otherwise, secondary correction by mandibular osteotomy, maxillary osteotomy or both may be appropriate to correct any residual occlusal and facial asymmetry (15). In general $\vec{\sigma}$ terms, the present case shows that, when condylectomy is performed and subsequent orthognathic surgery is necessary, this second operation is easier.

This is a case of severe jaw asymmetry due to severe unilateral $\mathrm{CH}$, which was managed with surgery and orthodontic treatment. The additional orthodontic treatment and orthognathic surgery were necessary for a better outcome since cosmetic and functional needs were achieved to the satisfaction of the patient. This case demonstrates the need for careful consideration of all the options that can be offered to patients with these types of problems.

\section{Resumo}

Hiperplasia condilar (HC) é um processo raro e auto-limitativo que ocorre

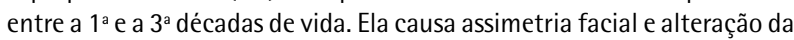
oclusão. 0 tratamento envolve ressecção da cabeça do côndilo e cirurgia ortognática. Este artigo descreve o caso de uma mulher de 37 anos com inicio espontâneo de $\mathrm{HC}$ e duração de aproximadamente 25 anos. 0 tratamento foi feito com ressecção apenas do côndilo, o que melhorou consideravelmente a assimetria facial e a oclusão em poucos meses de acompanhamento. Seguiu-se o tratamento ortodôntico e a paciente foi submetida a cirurgia ortognática três anos depois. Atualmente a paciente está satisfeita com sua aparência e função, sem apresentar sinais de recorrência.

\section{References}

1. Butt FM, Guthua SW, Nganga P, Edalia M, Dimba EA. One-stage treatment of acquired facial deformity caused by severe unilateral condylar hyperplasia. J Craniofac Surg 2011;22:1966-1968.

2. Ahn SJ, Lee SP, Nahm DS. Relationship between temporomandibular joint internal derangement and facial asymmetry in women. Am J
Orthod Dentofacial Orthop 2005;128:583-591.

3. Nitzan DW, Katsnelson A, Bermanis I, Brin I, Casap N. The clinical characteristics of condylar hyperplasia: experience with 61 patients. J Oral Maxillofac Surg 2008;66:312-318.

4. Cervelli V, Bottini DJ, Arpino A, Trimarco A, Cervelli G, Mugnaini F. Hypercondylia: problems in diagnosis and therapeutic indications. J Craniofac Surg 2008;19:406-410.

5. Obwegeser HL, Makek MS. Hemimandibular hyperplasiahemimandibular elongation. J Maxillofac Surg 1986;14:183-208.

6. Wolford LM, Morales-Ryan CA, Garcia-Morales P, Perez D. Surgical management of mandibular condylar hyperplasia type 1. Proc (Bayl Univ Med Cent) 2009;22:321-329.

7. Pereira-Santos D, De Melo WM, Souza FA, de Moura WL, Cravinhos JC. High condylectomy procedure: a valuable resource for surgical management of the mandibular condylar hyperplasia. J Craniofac Surg 2013;24:1451-1453.

8. Venturin JS, Shintaku WH, Shigeta Y, Ogawa T, Le B, Clark GT. Temporomandibular joint condylar abnormality: evaluation, treatment planning, and surgical approach. J Oral Maxillofac Surg 2010;68:11891196.

9. Utumi ER, Pedron IG, Perrella A, Zambon CE, Ceccheti MM, Cavalcanti MG. Osteochondroma of the temporomandibular joint: a case report. Braz Dent J 2010;21:253-258.

10. Wolford LM. Concomitant temporomandibular joint and orthognathic surgery. J Oral Maxillofac Surg 2003;61:1198-1204.

11. Vajgel A, de Santana Santos T, Camargo IB, Moraes de Oliveira D, Filho JR, de Holanda Vasconcellos RJ. Management of subcondylar fracture by intraoral approach. J Craniofac Surg 2013;24:587-588.

12. Olate S, Martinez F, Uribe F, Pozzer L, Cavalieri-Pereira L, Moraes M. TMJ function after partial condylectomy in active mandibular condylar hyperplasia. Int J Clin Exp Med 2014;7:775-779.

13. Stavropoulos F, Dolwick MF. Simultaneous temporomandibular joint and orthognathic surgery: the case against. J Oral Maxillofac Surg 2003;61:1205-1206.

14. Chen YR, Bendor-Samuel RL, Huang CS. Hemimandibular hyperplasia. Plast Reconstr Surg 1996;97:730-737.

15. Araújo FAC, Santos TS, Silva EDO, Laureano-Filho JR. Onestage treatment of hemimandibular hyperplasia. J Craniof Surg 2012;23:e635-e636.

Received February 19, 2012 Accepted February 21, 2014 